\title{
Effective cancer immunotherapy by natural mouse conventional type-1 dendritic cells bearing dead tumor antigen
}

Stefanie K. Wculek', Joaquín Amores-Iniesta', Ruth Conde-Garrosa', Sofía C. Khouili', Ignacio Melero 2,3,4 and David Sancho ${ }^{1 *}$ (D)

\begin{abstract}
Background: The manipulation of dendritic cells (DCs) for cancer vaccination has not reached its full potential, despite the revolution in cancer immunotherapy. DCs are fundamental for CD8+ T cell activation, which relies on cross-presentation of exogenous antigen on MHC-I and can be fostered by immunogenic cancer cell death. Translational and clinical research has focused on in vitro-generated monocyte-derived DCs, while the vaccination efficacy of natural conventional type $1 \mathrm{DCs}(\mathrm{CDC1s})$, which are associated with improved anti-tumor immunity and specialize on antigen cross-presentation, remains unknown.
\end{abstract}

Methods: We isolated primary spleen mouse CDC1s and established a protocol for fast ex vivo activation and antigenloading with lysates of tumor cells that underwent immunogenic cell death by UV irradiation. Natural tumor antigen-loaded CDC1s were transferred and their potential for induction of endogenous CD8+ and CD4+ T cell responses in vivo, cancer prevention and therapy were assessed in three grafted cancer models. Further, we tested the efficacy of natural CDC1 vaccination in combination and comparison with anti-PD-1 treatment in two "wildtype" tumor models not expressing exogenous antigens.

Results: Herein, we reveal that primary mouse CDC1s ex vivo loaded with dead tumor cell-derived antigen are activated and induce strong CD8+ $T$ cell responses from the endogenous repertoire upon adoptive transfer in vivo through tumor antigen cross-presentation. Notably, cDC1-based vaccines enhance tumor infiltration by cancerreactive CD8+ and CD4+ T cells and halt progression of engrafted cancer models, including tumors that are refractory to anti-PD-1 treatment. Moreover, combined tumor antigen-loaded primary CDC1 and anti-PD-1 therapy had strong synergistic effects in a PD-1 checkpoint inhibition susceptible cancer model.

Conclusions: This preclinical proof-of-principle study is first to support the therapeutic efficacy of cancer immunotherapy with syngeneic dead tumor cell antigen-loaded mouse $\mathrm{CDC1s}$, the equivalents of the human dendritic cell subset that correlates with beneficial prognosis of cancer patients. Our data pave the way for translation of cDC1-based cancer treatments into the clinic when isolation of natural human CDC1s becomes feasible.

Keywords: Conventional dendritic cells, cDC1, Cancer immunotherapy, Vaccination, Cell-associated antigen, Cross-presenting dendritic cells, Immunogenic cell death

\footnotetext{
* Correspondence: dsancho@cnic.es

${ }^{1}$ Immunobiology Laboratory, Centro Nacional de Investigaciones

Cardiovasculares (CNIC), Melchor Fernández Almagro, 3, 28029 Madrid, Spain

Full list of author information is available at the end of the article
}

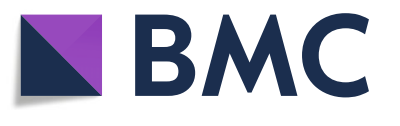

(c) The Author(s). 2019 Open Access This article is distributed under the terms of the Creative Commons Attribution 4.0 International License (http://creativecommons.org/licenses/by/4.0/), which permits unrestricted use, distribution, and reproduction in any medium, provided you give appropriate credit to the original author(s) and the source, provide a link to the Creative Commons license, and indicate if changes were made. The Creative Commons Public Domain Dedication waiver (http://creativecommons.org/publicdomain/zero/1.0/) applies to the data made available in this article, unless otherwise stated. 


\section{Background}

Cytotoxic CD8+ T lymphocytes (CD8+ CTLs) are key effector cells that recognize and eliminate tumor cells and therefore preferential targets for improving cancer immunotherapy [1]. However, cancer-reactive CD8+ T cells can become dysfunctional or exhausted limiting their efficacy [2]. Immune checkpoint inhibitors, such as anti-PD-1 or anti-CTLA4, have achieved unprecedented success in the treatment of various cancers by reinvigorating exhausted CD8+ CTLs. Unfortunately, their clinical benefits remain limited and it is crucial to find additional strategies to increase basal anti-tumor CD8+ T cell immunity $[3,4]$.

Dendritic cell (DC) vaccines may elicit and improve anti-cancer CD8+ $\mathrm{T}$ cell immunity [5, 6]. However, the use of DCs for tumor immunotherapy has been limited so far, being the only FDA-approved therapy the blood antigen (Ag)-presenting cell-based vaccine Sipuleucel-T for metastatic castration-resistant prostate cancer [7]. Currently, most clinical efforts focus on human blood monocyte-derived DCs (moDCs) cultured for several days with GM-CSF and IL-4, loaded with various Ags and stimulated with proinflammatory adjuvants [6, 8-10]. Numerous clinical trials are ongoing that test the efficacy of moDC-based vaccination against different types of cancer as single agents or combination therapies. Combination of DC vaccination and immune checkpoint inhibitors appears especially promising, as both target enhanced mobilization and activity of anti-cancer CD8+ T cells $[5,6,11]$. In general, adoptive transfer of ex vivo-treated DCs to cancer patients demonstrated an excellent safety profile, but the efficacy did not meet the expectations yet [12].

The advance in understanding of distinct DC subset functions calls for the development of next-generation DC vaccines, by using primary DC subsets from patient blood that excel in induction of anti-cancer CD8+ T cell immunity $[8,10,11,13,14]$. Circulating human DC subsets comprise two types of conventional (c) DCs, cDC1s (BDCA3+ cDCs) and cDC2s (CD1c+ cDCs) as well as plasmacytoid DCs (BDCA2+ BDCA4+ pDCs), which specialize on different functions [15]. Both human pDCs and $\mathrm{cDC} 2 \mathrm{~s}$ from blood have been used as basis for next-generation DC vaccines [16, 17], which led to an ongoing phase III clinical trial (ClinicalTrials.gov identifier: NCT02993315).

Human cDC1s (DNGR-1/CLEC9A+, XCR1+) and their mouse equivalents (DNGR-1/Clec9a+, Xcr1+, also expressing CD8 in lymphoid organs) are strong inducers of CD8+ $\mathrm{T}$ cell responses due to their superior capacity for uptake of dying or dead cell material and processing of cancer cell-associated Ags for cross-presentation [18-22]. Moreover, $\mathrm{cDC} 1 \mathrm{~s}$ are the main cellular source of IL-12 [23], a fundamental cytokine for anti-cancer CD8+ CTL activation [24]. Those functional traits support the notion that $\mathrm{CDC} 1 \mathrm{~s}$ are the superior $\mathrm{DC}$ subset for induction of anti-tumor immunity [25, 26]. Indeed, Batf3-dependent cDC1s are needed to mount anti-tumor CD8+ T cell responses at baseline [25] or upon poly I:C therapy [27] and are indispensable for efficacy of immune checkpoint blockade [28, 29]. Moreover, cDC1s are critical for the transport of intact tumor-Ag to lymph nodes (LNs) to elicit anti-tumor $\mathrm{T}$ cell activation [29, 30] and the secretion of CXCL9/10 by tumor-infiltrating cDC1s is crucial for the recruitment of CD8+ T cells into tumors [31]. Moreover, a variety of studies show that presence of cross-presenting $\mathrm{BDCA} 3+\mathrm{CDC} 1 \mathrm{~s}$ or their gene signatures in the tumor correlates with enhanced $\mathrm{T}$ cell infiltration, improved prognosis and survival of cancer patients [26, 30, 32, 33].

Despite these evidences, natural $\mathrm{cDC} 1 \mathrm{~s}$ have not been previously tested as a syngeneic vaccine in cancer therapy. We herein demonstrate the feasibility and efficacy of an anti-cancer treatment based on adoptive transfer of the natural cross-presenting mouse $\mathrm{CDC1}$ subset loaded ex vivo with an autologous whole tumor cell lysate (TCL) obtained after induction of immunogenic cell death (ICD) by UV irradiation. The $\mathrm{CDC1}$ vaccine induces substantial anti-tumor $\mathrm{CD} 8+\mathrm{T}$ cell responses from the endogenous repertoire in vivo, that depend on their cell-autonomous cross-presentation potential. Notably, this treatment fosters tumor-reactive CD8+ and $\mathrm{CD} 4+\mathrm{T}$ cell presence in tumors and tumor-draining LNs (tdLN), limiting tumor progression of three different mouse cancer models, of which two do not express exogenous or dominant Ags. TCL-loaded CDC1 administration profoundly improves anti-PD-1 therapy in an immune checkpoint antibody sensitive model and, notably, is also effective for treatment of tumors that are refractory to anti-PD-1. Therefore, we provide valuable pre-clinical information on the efficacy of therapeutic cDC1-based anti-cancer vaccination for the development of next-generation DC vaccines [8].

\section{Methods \\ Mice}

Mouse colonies were bred at the CNIC under specific pathogen-free conditions. Wildtype mice were in C57BL/6 background and 6-10-weeks old females used for all experiments. B6.C-H2- $\mathrm{K}^{\mathrm{bm} 1}$ (B6.C-H2-K ${ }^{\mathrm{bm} 1} / \mathrm{ByJ}$ or $\mathrm{C} 57 \mathrm{BL} /$ $6^{\mathrm{H} 2 K b m 1}$ ) mice were kindly provided by Caetano Reis e Sousa (The Crick Institute, London, UK) and OT-I transgenic mice (C57BL/6-Tg (TcraTcrb)1100Mjb/J) crossed with B6-SJL (Ptprca Pepcb/BoyJ) mice expressing the CD45.1 allele were both from The Jackson Laboratory (Bar Harbor, ME, USA).

Tissue dissociation for cell isolation

Spleen and inguinal lymph nodes (iLNs) were harvested in R10 medium [RPMI Medium $1640\left(\mathrm{Gibco}^{\circ}\right)$ with $10 \%$ 
heat-inactivated Fetal Bovine Serum (hi-FBS), $50 \mu \mathrm{M}$ $\beta$-Mercaptoethanol (both Sigma), $2 \mathrm{mM}$ L-Glutamine, $100 \mathrm{U} / \mathrm{mL}$ Penicillin and Streptomycin $(100 \mu \mathrm{g}$ both Lonza), $0.1 \mathrm{mM}$ NEAA, $1 \mathrm{mM}$ Sodium Pyruvate, $1 \mathrm{mM}$ HEPES (all from HyClone $\left.{ }^{\mathrm{rm}}\right)$ ]. Spleen was digested for 10 min with $0.25 \mathrm{mg} / \mathrm{ml}$ Liberase TL (Roche) and $50 \mu \mathrm{g} / \mathrm{ml}$ DNaseI (Sigma Aldrich). Tumors were minced and incubated for $30 \mathrm{~min}$ in $\mathrm{HBSS}\left(\mathrm{Gibco}^{\circ}\right)$ with $0.5 \mathrm{mg} /$ $\mathrm{ml}$ Collagenase IV (Sigma) and $50 \mu \mathrm{g} / \mathrm{ml}$ DNAseI shacking at $37^{\circ} \mathrm{C}$. Tissues were squeezed through a $70 \mu \mathrm{m}$ cell strainer (Corning), re-filtered through a $40 \mu \mathrm{m}$ cell strainer and spleen subjected for $5 \mathrm{~min}$ to Red Blood Cell Lysis Buffer (Sigma).

\section{Purification and adoptive transfer of CD8+ spleen DCs}

For $\mathrm{cDC} 1$ expansion, $2.5 \times 10^{6}$ B16-Flt3L cells in $100 \mu \mathrm{l}$ PBS were inoculated subcutaneously into both flanks of wildtype or $\mathrm{C} 57 \mathrm{BL} / 6^{\mathrm{H} 2 \mathrm{Kbm} 1}$ mice and spleens harvested 9-11 days thereafter or naïve mice used. Spleen CD8+ cDC1 cells were isolated using the mouse CD8+ Dendritic Cell Isolation Kit (Order no. 130-091-169) using $\mathrm{MACS}^{\circ}$ columns and autoMACS ${ }^{\mathrm{Tw}}$ Running Buffer according to manufacturer's instructions (Miltenyi Biotec). In brief, spleen single cell suspensions were subjected to negative selection that depletes T, B and NK cells, followed by positive selection of CD8a DCs. Purified $\mathrm{cDC1s}$ were cultured in round-bottom 96-well plates (Corning) at $2 \times 10^{5} \mathrm{cDC} 1 \mathrm{~s} / 200 \mu \mathrm{l} \mathrm{R} 10$ medium for $1 \mathrm{~h}$ at $37^{\circ} \mathrm{C}$ in $5 \% \mathrm{CO}_{2}$ together with (as specified for experiments): $20 \mu \mathrm{g} / \mathrm{ml}$ poly I:C LMW (InVivoGen), $20 \mu \mathrm{g} / \mathrm{ml}$ Hiltonol (kindly provided by Andres Salazar from Oncovir), $20 \mu \mathrm{g} / \mathrm{ml}$ BO112 (Bioncotech Therapeutics), $20 \mu \mathrm{g} / \mathrm{ml}$ endotoxin-free soluble OVA protein (EndoGrade from Hyglos), and/or B16-OVA, B16/F10 or MC38 TCL at a ratio of $1 \mathrm{DC}$ to 2 tumor cells. cDC1s were washed with R10 and, when incubated with TCL, re-purified using MACS $^{\circ}$ columns. Cells were kept in culture for $4 \mathrm{~h}$ for analysis of CD86 and MHC-II induction, immediately added to naive OT-I cells or $2-10 \times$ $10^{5} \mathrm{cDC} 1 \mathrm{~s}$ injected intravenously $\left(100 \mu \mathrm{PBS}, \mathrm{Gibco}^{\circ}\right)$ or intradermally $(50 \mu \mathrm{l}$ PBS) into mice. Anti-PD-1 (clone RMP1-14 from BioXCell) was administered intraperitoneal at $100 \mu \mathrm{g} /$ mouse in $100 \mu \mathrm{l}$ PBS.

\section{OT-I CD8+ T cell assays}

Total spleen CD8+ OT-I cells for in vivo assays were purified from CD45.1 OT-I transgenic mice by negative selection as follows: 30 min incubation of spleen single cell suspensions with biotinylated antibodies (all BD Biosciences) for anti-mouse CD16/CD32 (clone 2.4G2), CD4 (clone GK1.5), B220 (clone RA3-6B2), CD11c (clone HL3), CD11b (clone M1/70), Gr-1 (clone RB6-8C5) and I-A/I-E (MHC-II, clone 2G9) at $4{ }^{\circ} \mathrm{C}$ shaking, washing, $20 \mathrm{~min}$ incubation with Streptavidin
MicroBeads in autoMACS ${ }^{\mathrm{Tu}}$ Running Buffer and magnetic separation using LD columns (all Miltenyi Biotec) according to manufacturer's instructions. For ex vivo proliferation assay, naive CD8+ CD44- CD62L+ OT-I cells were isolated by flow cytometric sorting using the SY3200 Cell Sorter (Sony Biotechnology). Cells were labeled with CellTrace ${ }^{\mathrm{m}}$ Violet Cell Proliferation Kit (Thermofisher, Molecular Probes) according to manufacturer's instructions. $1-2 \times 10^{5}$ total labeled OT-I cells in $100 \mu \mathrm{l}$ PBS were injected intravenously into mice. Naive OT-I cells were cultured for 3 days with pre-treated $\mathrm{cDC1s}$ in $\mathrm{R} 10$ medium (1:1 ratio) in round-bottom 96-well plates at $37^{\circ} \mathrm{C}$ in $5 \% \mathrm{CO}_{2}$ followed by flow cytometric analysis of proliferation by dilution of the CellTrace $^{\text {Tu }}$ Violet dye.

\section{Fluorescent staining, flow cytometry and cell sorting}

Single cell suspensions of $\mathrm{cDC} 1 \mathrm{~s}$, spleen, iLN and tumors or cultured OT-I cells were incubated for $20 \mathrm{~min}$ at $4{ }^{\circ} \mathrm{C}$ in PBS with $2 \%$ hi-FBS and $0.5 \mathrm{mM}$ EDTA (Sigma) with FcR block anti-mouse CD16/CD32 (2.4G2, Tonbo Biosciences) and a mix of the following fluorochrome-conjugated antibodies: anti-mouse CD45.1 (clone A20), CD44 (clone IM7), SIRP $\alpha$ (clone P84) and CD62L (MEL-14) from eBioscience ${ }^{\mathrm{ms}}$, CD11c (clone HL3), CD11b (clone M1/70), and I-A/I-E (MHC-II, clone 2G9) from BD Biosciences, CD3 (clone 17A2), CD86 (clone GL-1) and PD-1 (clone J43.1) from Tonbo Biosciences, CD8 (clone 53-6.7) from BioLegend, XCR1 (clone REA707), CD205 (clone NLDC-145), Clec9A (clone 7H11) and CD24 (clone M1/69) from Miltenyi Biotec. When indicated, cells were beforehand incubated with Allophycocyanin-conjugated OVA H-2Kb (257SIINFEKL-264) dextramer (Immunodex, catalogue number JD2163) or a mix of allophycocyanin-conjugated OVA-specific MHC-II tetramers (I-A(b) 329-AAHA EINEA-337, I-A(b) 328-HAAHAEINEA-337 and I-A(b) 325-QAVHAAHAEIN-325; all from the NIH Tetramer Facility at Emory University) for $20 \mathrm{~min}$ at room temperature. Hoechst 332558 (Sigma) or SYTOX Green (Thermofisher) was used to exclude dead cells. The LSRFortessa cell analyzer running FACSDiva software (BD Biosciences) and FlowJo Version 10 or FCS Express 6 Plus software was used to record and analyze data.

\section{Tumor cell culture, inoculation, in vivo analysis and HMGB1 ELISA}

B16/F10 (a kind gift from I. Malanchi, The Crick Institute, London, UK), B16-OVA (a kind gift from L. Chen, Yale University, New Haven, CT), MC38 (purchased from the ATCC) [28] and B16-Flt3L cells (kindly provided by G. Dranoff, Harvard University, Boston, MA) [34] were cultured at $37{ }^{\circ} \mathrm{C}$ in $5 \% \mathrm{CO}_{2}$ in $\mathrm{R} 10$ medium. The B16-OVA cell line expresses a truncated and non-secreted OVA 
protein without the signal peptide as a fusion protein with EGFP-C1, as previously described for mouse embryonic fibroblasts [35]. All cell lines were tested for absence of mycoplasma using the MycoAlert PLUS Mycoplasma Detection Kit (Lonza) according to manufacturer's instructions. Tumor cells were detached (5 mM EDTA/PBS) before reaching confluence and $1 \times 10^{6}$ B16-OVA or $0.5 \times$ $10^{6} \mathrm{~B} 16 / \mathrm{F} 10$ cells inoculated intradermal or $0.5 \times 10^{6}$ MC38 cells inoculated subcutaneous in $50 \mu \mathrm{l}$ PBS into the shaved right flank of wildtype mice. Tumor size was measured three times weekly using a digital caliper (Ratio), calculated as the product of orthogonal diameters and is displayed in $\mathrm{mm}^{2}$. Tumor-bearing mice were monitored daily and sacrificed to determine the survival curve when signs of adverse effects (pain, apathy, dehydration, necrotic tumor) were observed or the humane endpoint (tumor size diameter $1.7 \mathrm{~cm}$ ) reached. Pictures were taken at indicated time points using a digital camera. For HMGB1 ELISA, $0.5 \times 10^{6}$ cancer cells were UV-irradiated or treated with doxorubicin $(25 \mu \mathrm{M})$, brefeldin $\mathrm{A}(50 \mu \mathrm{M})$

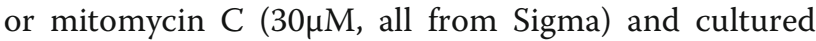
in $1 \mathrm{ml} \mathrm{R} 10$ for $18 \mathrm{~h}$, supernatant harvested and solid components removed by centrifugation. HMGB1 was measured using the HMGB1 ELISA (IBL international $\mathrm{GmbH}$ ) following manufacturer's instructions.

\section{Tumor cell lysate preparation}

B16-OVA, B16/F10 or MC38 tumor cells were adjusted to $4 \times 10^{6}$ cells $/ \mathrm{ml}$ in R10 medium, $1.5 \mathrm{ml}$ per well plated in 6-well plates (Corning) and treated with $300 \mathrm{~mJ} / \mathrm{cm}^{2}$ UV irradiation using a Stratalinker UV Crosslinker 1800 (Stratagene). Cells were cultured for $16-24 \mathrm{~h}$ at $37^{\circ} \mathrm{C}$ in $5 \% \mathrm{CO}_{2}$, subjected to 3 freeze $\left(-80^{\circ} \mathrm{C}\right) /$ thaw $\left(37^{\circ} \mathrm{C}\right)$ cycles of minimum $30 \mathrm{~min}$ each and passed through a $40 \mu \mathrm{m}$ cell strainer before addition to $\mathrm{CDC} 1 \mathrm{~s}$ at a ratio of 1 DC to 2 tumor cells. B16-OVA TCL was twice washed with R10 and centrifuged at full-speed to remove soluble components and obtain "washed B16-OVA TCL".

\section{Spleen, tdLN and tumor re-stimulation}

For intracellular IFN $\gamma$ staining, single cell suspensions were ex vivo re-stimulated with $2 \mu \mathrm{M} \mathrm{OVA}_{257-264}$ peptide (SIINFEKL, GenScript), OVA $323-339$ peptide (ISQAV HAAHAEINEAGR, GenScript)-loaded or B16-OVA TCL-loaded antigen-presenting cells (APCs) for $2 \mathrm{~h}$ in $\mathrm{R} 10$ at $37{ }^{\circ} \mathrm{C}$ in $5 \% \mathrm{CO}_{2}$ followed by $5 \mu \mathrm{g} / \mathrm{mL}$ Brefeldin A (Sigma Aldrich) treatment for $4 \mathrm{~h}$. Cells were labeled with indicated surface-staining antibodies, fixed with $4 \%$ PFA (Thermofisher), permeabilized with $1 \%$ Bovine Serum Albumin, 0.1\% Saponin, 0.02\% Sodium Azide (all Sigma) in PBS and stained with Allophycocyanin-conjugated anti-mouse IFNY antibody (clone XMG1.2, eBioscience $\left.\mathrm{e}^{\mathrm{mm}}\right)$. APCs were generated from bone marrow cells, harvested by flushing the tibia and femur and a red blood cell lysis. Then, bone marrow was cultured in R10 with $20 \mathrm{ng} / \mathrm{ml}$ murine GM-CSF (Peprotech) for 7 days; floating cells were harvested and incubated with either $5 \mu \mathrm{M}$ OVA $_{323-339}$ peptide or B16-OVA TCL for $8 \mathrm{~h}$ followed by addition of $100 \mathrm{ng} / \mathrm{ml}$ LPS-EK (InvivoGen) for another $12 \mathrm{~h}$.

\section{RNA isolation and quantitative PCR}

Total RNA was extracted with the RNeasy Micro Kit (Qiagen) and reverse transcribed using the High Capacity cDNA Reverse Transcription Kit with random hexamers (Applied Biosystems ${ }^{\circ}$ ) following manufacturer's instructions. Quantitative PCR was performed using the GoTaq $^{\circ}$ qPCR Master Mix (Promega) in a 7900 HT Fast Real-Time PCR System (Applied Byosystem ${ }^{\circ}$ ). $2^{-\Delta C t}$ mRNA expression values of mouse Ifnb1, Il12b, CD40 and $C C R 7$ were calculated relative to expression of $A c t b$. Primers (Sigma):

Actb-sense (5')-GGCTGTATTCCCCTCCATCG-(3'), Actb-antisense (5')-CCAGTTGGTAACAATGCCA TGT-(3'); Ifnb1-sense (5')-TCAGAATGAGTGGTGGTTGC-(3'), Ifnb1-antisense (5')-GACCTTTCAAATGCAGTAG ATTCA-(3'); Ill2b-sense (5')-GGAAGCACGGCAGCAGAATA-(3'), $I l 12 b$-antisense (5')-AACTTGAGGGAGAAGTAGG AATGG-(3'); CD40-sense (5')-TTGTTGACAGCGGTCCATCTA-(3'), CD40-antisense (5')-GCCATCGTGGAGGTACTGT TT-(3'); CCR7-sense (5')-TGTACGAGTCGGTGTGCTTC-(3'), CCR7-antisense (5')-GGTAGGTATCCGTCATGGT CTTG-(3').

\section{Statistical analysis}

Data analyses employed GraphPad Prism version 7.0c. Data are presented as mean \pm standard error of the mean, individual values, staircase graph with ticks, 'scatter plot with box \& whiskers' and/or 'scatter plot with column bar' graph and were analyzed using Two-tailed Student's $t$-test (Paired or unpaired according to experimental setting), One-way ANOVA and Tukey post hoc test, Mantel-Cox test and Two-way ANOVA. All experiments were repeated at least twice and either representative experiments or pooled data from several experiments are shown as indicated in the figure legends. Mice were allocated randomly in different experimental groups, but no blinding or randomization strategy was used. No animals were excluded from analysis, unless they had wounds from fighting/over-grooming. All $n$ values represent biological replicates (different mice, primary cell preparations or in vitro experiments). Differences were considered significant when $P<0.05$ and are 
indicated as ns, not significant, ${ }^{*} P<0.05,{ }^{* *} P<0.01$, ****: $P<0.001$

\section{Results}

Adoptive transfer of antigen and adjuvant-treated natural mouse $\mathrm{CDC} 1 \mathrm{~s}$ promotes $\mathrm{CD} 8+\mathrm{T}$ cell immunity

Comparative transcriptional and functional analyses have established that mouse spleen $\mathrm{CD} 8 \alpha+\mathrm{cDC} 1 \mathrm{~s}$ are the equivalents of human circulating $\mathrm{BDCA} 3+\mathrm{cDC} 1 \mathrm{~s}$ [18-21]. Therefore, we used naturally occurring mouse spleen $\mathrm{CD} 8 \alpha+\mathrm{CDC} 1$ in order to test the suitability of cDC1s as basis for effective cancer therapy. Human anti-cancer DC vaccines are based on autologous DCs obtained from the cancer patient [36]. To reproduce this situation in our pre-clinical setting while expanding cDC1s, mice were grafted with B16 melanomas that secrete FMS-like tyrosine kinase 3 ligand (FLT3L) (B16-FLT3L) [34]. CD11c+ MHC-II+ CD8 $\alpha+$ cDC1s isolated from the spleen of both steady-state and B16-FLT3L tumor-bearing donor mice showed similar patterns of surface markers, including high XCR1, CD205, Clec9A and CD24, as well as no/low CD11b and SIRP $\alpha$ expression (Additional file 1: Figure S1), suggesting no major phenotypic alteration of $\mathrm{CDC} 1 \mathrm{~s}$ in B16-FLT3L tumor-bearing mice.

To address the efficacy of naturally occurring $\mathrm{cDCls}$ for the induction of CD8+ T cell immunity upon transfer in vivo, we treated $\mathrm{cDC1s}$ ex vivo with soluble Ovalbumin (OVA) as $\mathrm{Ag}$ and poly $\mathrm{I}: \mathrm{C}$, a synthetic doublestranded RNA adjuvant that binds Toll-like receptor (TLR) 3, which is selectively expressed by mouse and human $\mathrm{CDC} 1 \mathrm{~s}$ and promotes their activation and function [20, 27]. Indeed, poly I:C treatment ex vivo rapidly activated natural mouse $\mathrm{cDC1} 1 \mathrm{~s}$, inducing transcription of cytokines and surface receptors involved in CD8+ T cell priming (Fig. 1a). Natural cDC1s were then intravenously (IV) injected into syngeneic recipient mice that were previously adoptively transferred with OT-I OVA-specific CD8+ T cells (Fig. 1b). Adoptive transfer of natural cDC1s shortly exposed to OVA and poly I:C ex vivo led to increased OT-I proliferation, frequencies in CD8+ $\mathrm{T}$ cells and total numbers, as well as augmented IFN $\gamma$ producing OT-I cells after specific MHC-class I OVA $257-264$ peptide re-stimulation, as compared with mice transferred with $\mathrm{CDC} 1 \mathrm{~s}$ pre-treated only with OVA or poly I:C (Fig. 1c-f). Hence, natural spleen cDC1s treated ex vivo with Ag and adjuvant for just $1 \mathrm{~h}$ strongly activate CD8+ T cells in vivo in an adjuvant and Ag-dependent fashion.

Tumor cell lysate-loaded CDC1s generate optimal CD8+ T cell activation in vivo

Most Ag preparations and delivery regimes for induction of anti-tumor immunity have been optimized for in vitro-generated moDCs and may be not equally suitable for natural DC subsets with specific intrinsic functional properties. Utilization of a variety of different tumor-associated Ags is likely to enhance the efficacy of DCs to mount a general anti-cancer immune response and thereby limits the escape of individual tumor-Ag variant loss. Enticingly, ICD of tumor cells induced by methods such as UV irradiation induces strong DC-mediated immunity to dead-cell associated Ags $[37,38]$. Therefore, we prepared syngeneic TCL of total mouse cancer cells by UV irradiation, followed by culture $\mathrm{o} / \mathrm{n}$ to allow secondary necrosis and 3 freeze/thaw cycles to ensure cell death (Additional file 1: Figure S2a). UV irradiation induced release of high-mobility group box protein 1 (HMGB1), a hallmark of ICD, by OVA-expressing B16 melanoma cells (B16-OVA) [28], even higher than the strong ICD-inducer doxorubicin, whereas the non-ICD inducers mitomycin $\mathrm{C}$ and brefeldin A [38, 39] had no effect (Fig. 2a). ICD-mediated HMGB1 release results in DC activation and cross presentation [40, 41]. In line, natural spleen cDC1s treated ex vivo with B16-OVA TCL upregulated CD86 and MHC-II expression, which was dependent on soluble factors as washed TCL failed to do so (Fig. 2b and Additional file 1: Figure S2b). Addition of the potent stimulant poly I:C during TCL treatment further amplified their maturation, while CD86 levels remained slightly higher in TCL-treated $\mathrm{cDC} 1 \mathrm{~s}$ compared to controls (Fig. 2b and Additional file 1: Figure S2b). To determine optimal $\mathrm{cDC} 1$ activation, $\mathrm{cDC} 1 \mathrm{~s}$ were exposed to B16-OVA TCL in the presence of poly I:C (from InvivoGen), $\mathrm{Hiltonol}^{-}$(poly ICLC from Oncovir Inc., in clinical use) or BO-112 (a synthetic dsRNA complex targeting cytosolic helicases MDA5 and RIG-I as well as TLR3, in clinical trials: ClinicalTrials.gov identifier: NCT02828098). B16-OVA TCL-loaded and poly $\mathrm{I}: \mathrm{C}$-treated $\mathrm{CDC} 1 \mathrm{~s}$ showed the strongest potential to induce naive OT-I CD8+ T cell proliferation ex vivo, while the clinical-grade poly I:C analogues BO-112 and $\mathrm{Hiltonol}^{\circ}$ were less effective (Fig. 2c). Hence, we focused on poly I:C as optimized adjuvant for primary mouse spleen $\mathrm{cDC} 1 \mathrm{~s}$.

Next, we tested the efficiency of in vivo administration of cDC1s treated with B16-OVA TCL and poly I:C in mice adoptively transferred with OT-I CD8+ T cells. Notably, cDC1s treated with B16-OVA TCL and poly I:C induced increased total OT-I number and frequency as well as augmented IFNY production upon $\mathrm{OVA}_{257-264}$ re-stimulation of splenocytes compared with poly I:C + soluble OVAtreated $\mathrm{cDC1s}$ and additional control treatments without cDC1s or without Ag (Fig. 2d and Additional file 1: Figure S2c \& d). This observation pointed towards the efficacy of UV irradiation-induced TCL as an optimal Ag source for natural $\mathrm{cDC} 1 \mathrm{~s}$ fostering their activation. 


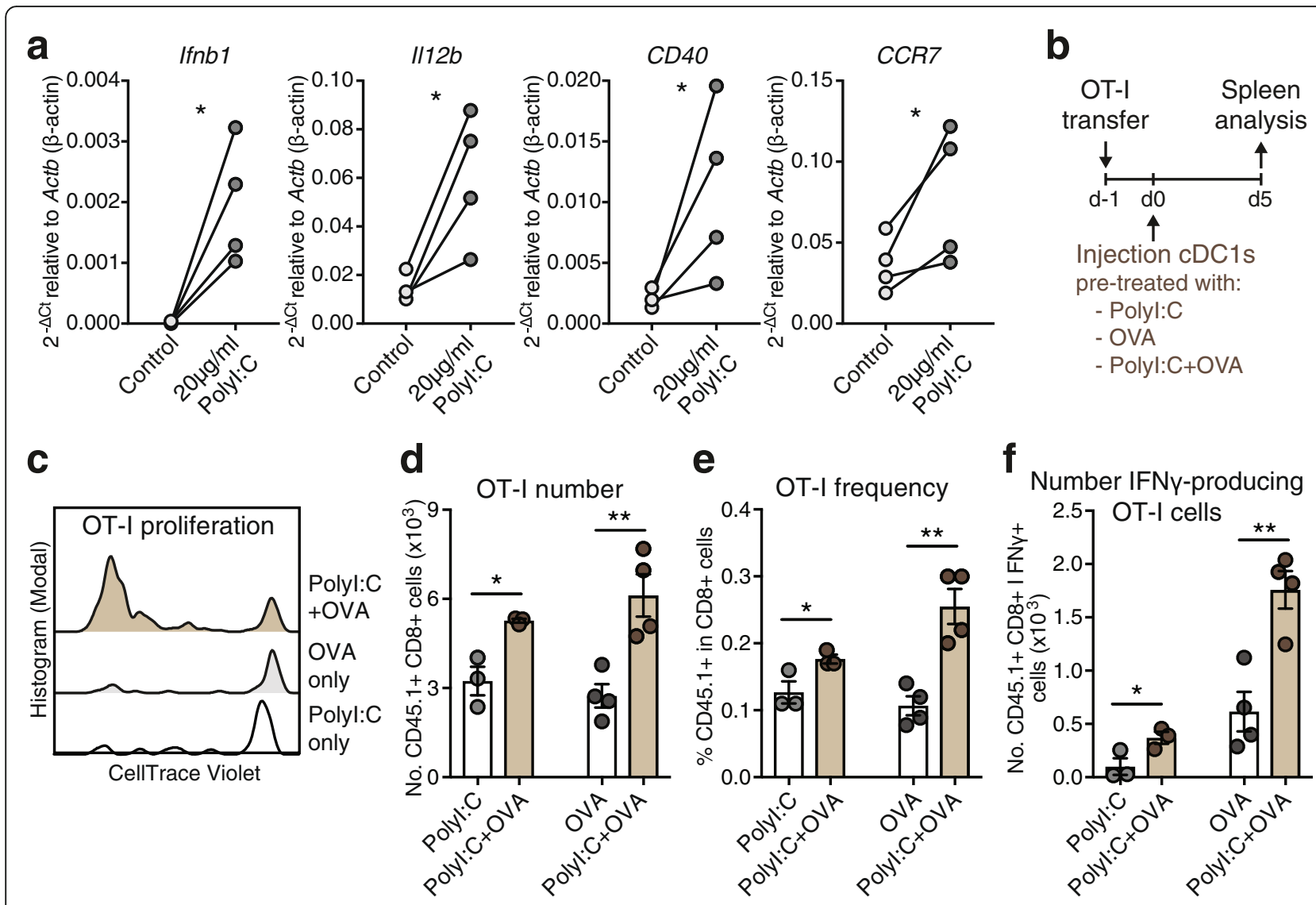

Fig. 1 Adoptive transfer of $\mathrm{Ag}$ and adjuvant-treated natural mouse $C D C 1$ s promotes CD8+ T cell immunity. a Quantitative PCR analyses of mRNA levels of Ifnb1 (IFN $\beta$ protein), II12b (IL12-p40 protein), CD40 and CCR7 relative to Actb ( $\beta$-actin protein) of spleen CDC1s freshly isolated from B16-FLT3L tumor-bearing mice and treated with $20 \mathrm{\mu g} / \mathrm{ml}$ poly I:C (InvivoGen) for $1 \mathrm{~h}$ ex vivo, $n=4$ spleen cDC1 preparations. ${ }^{*} P<0.05$ by Ratio paired Student's $t$ test. Ct: Cycle threshold, $-\Delta C t=-(C t$ [gene of interest] - Ct [Actb internal control gene]). $\mathbf{b}$ Schematic representation of experimental setup for data shown in c-f. Spleen CDC1s from B16-FLT3L tumor-bearing mice were cultured with $20 \mu \mathrm{g} / \mathrm{ml}$ poly l:C and/or $20 \mu \mathrm{g} / \mathrm{ml}$ soluble OVA protein for $1 \mathrm{~h}$, washed and $2 \times 10^{5} \mathrm{CDC} 1 \mathrm{~s}$ injected intravenously into CD45.2+ recipient mice that had been adoptively transferred with $1-2 \times 10^{5}$ CellTrace-Violet (CV)-labelled CD45.1+ OT-I CD8+ T cells one-day prior. c Representative flow cytometric analysis of OT-I T cell proliferation via CV-dilution in the spleen at day 5, gated on CD45.1+CD8+ OT-I cells. d-f f Flow cytometric quantification of $\mathbf{d}$ total OT-I cell number, e OT-I frequency in CD8+ cells and $\mathbf{f}$ number of IFNY-producing OT-I cells after re-stimulation with $\mathrm{OVA}_{257-264}$ peptide in the spleen at day 5 post-cDC1 injection. One representative of 2 independent experiments ( $n=3-4$ mice/group/experiment) is shown. ${ }^{*} P<0.05$, ${ }^{* *} P<0.01$ by Student's $t$ test

Once established an optimal adjuvant-Ag combination, we tested administration of TCL-loaded cDC1s via intradermal (ID) or IV injection in OT-I transferred mice. IV injection of B16-OVA TCL-loaded $\mathrm{cDC} 1 \mathrm{~s}$ induced strong OT-I T cell responses in the spleen but minor effects in the iLN, while ID administration induced strong OT-I expansion both in the spleen and the draining iLN (Fig. 2e). This result suggested ID administration as the optimal injection route for TCL-loaded $\mathrm{cDC} 1 \mathrm{~s}$ for treatment of tumors growing in the skin such as melanoma.

\section{Tumor Ag-loaded CDC1s cross-prime endogenous CD8+ T cells}

We aimed to determine the potency of TCL-loaded $\mathrm{cDC} 1 \mathrm{~s}$ to stimulate effector responses from the endogenous repertoire of CD8+ $\mathrm{T}$ cells (Fig. 3a). Following ID administration of B16-OVA TCL-loaded $\mathrm{cDC} 1 \mathrm{~s}$ to naive mice, we found increased cellularity in the iLN, including augmented numbers of CD8+ $\mathrm{T}$ cells and higher frequency and numbers of activated OVA-specific $\left(\mathrm{H}-2 \mathrm{~Kb}-\mathrm{OVA}_{257-264}+\right.$ ) CD8+ $\mathrm{T}$ cells (Fig. 3b \& $\mathrm{c}$ and Additional file 1: Figure S3a). These data show that transferred TCL-loaded CDC1s prime endogenous CD8+ T cells. Of note, the whole TCL contains other Ags in addition to OVA, which would increase the total number of $\mathrm{cDC} 1$ vaccine-induced endogenous anti-tumor CD8+ T cells.

Next, we evaluated if the observed induction of endogenous CD8+ $\mathrm{T}$ cell responses in vivo was dependent on cross-presentation on MHC-I of the ex vivo acquired tumor-Ag by the transferred cDC1s. cDC1s were obtained from B16-FLT3L tumor-grafted WT and C57BL/ $6^{\mathrm{H} 2 \mathrm{Kbm} 1}\left(\mathrm{H}-2 \mathrm{~K}^{\mathrm{bm} 1}\right)$ mice, which harbor a mutation in 


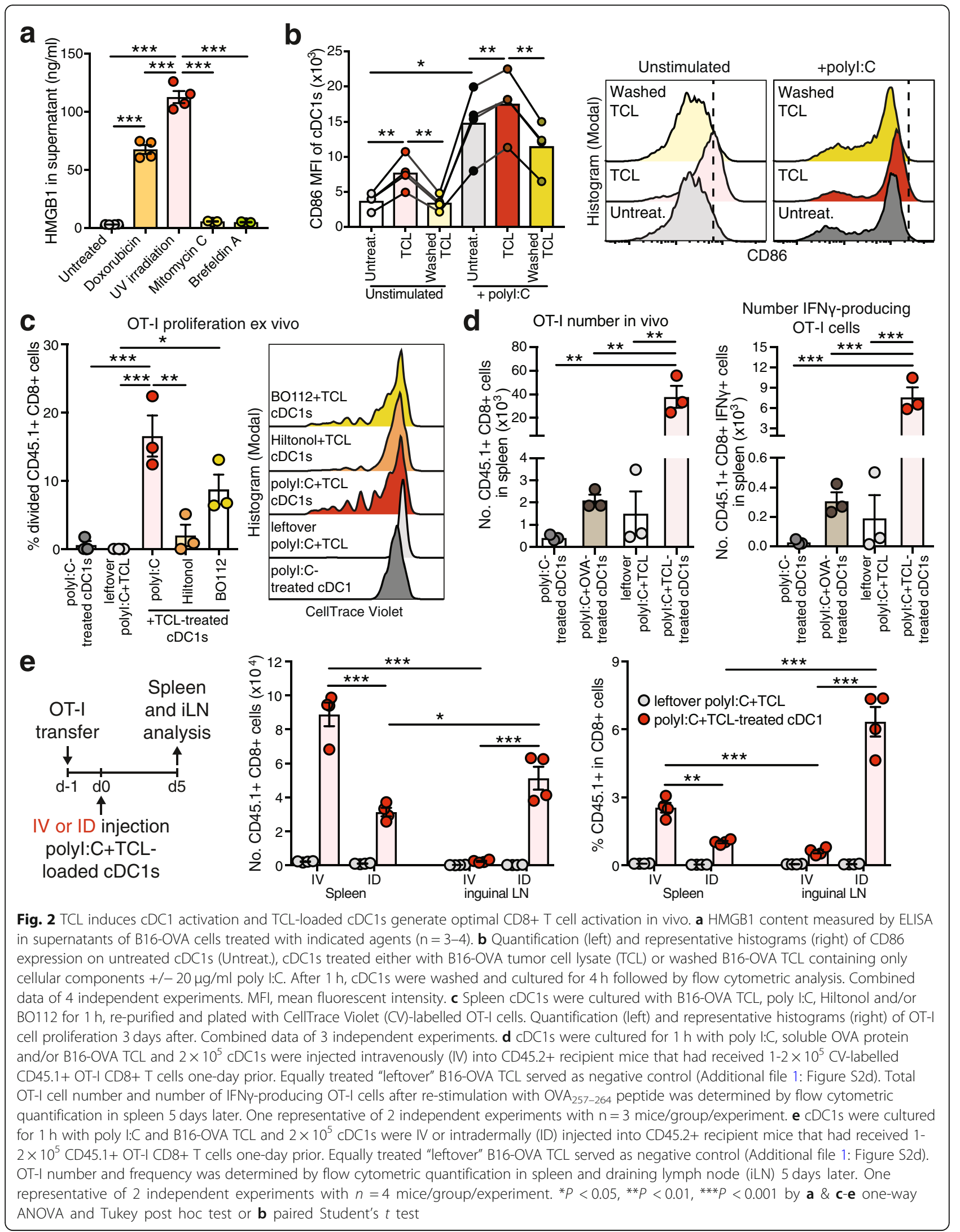




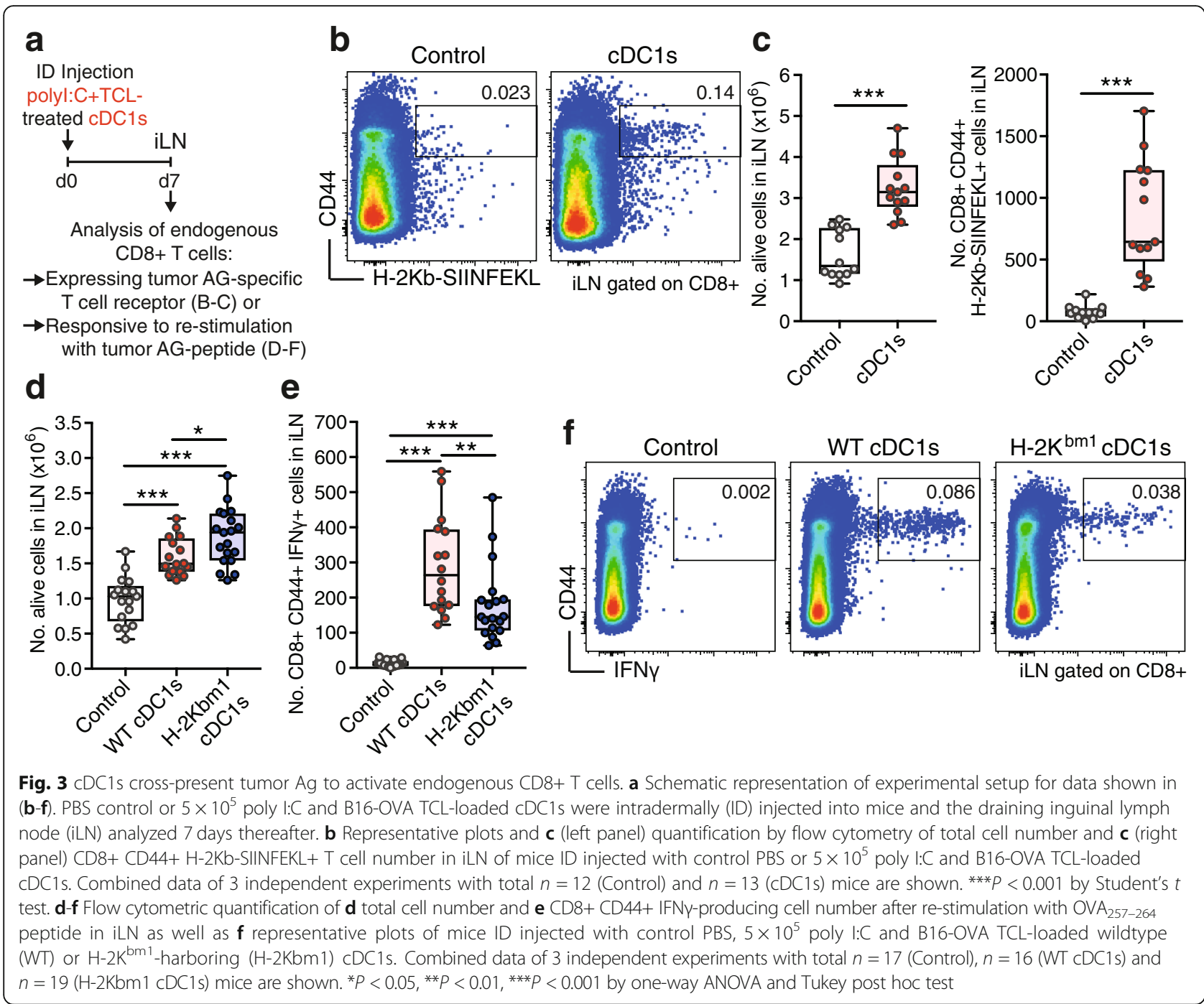

the $\mathrm{H}-2 \mathrm{~K}$ MHC-I molecule preventing the presentation of $\mathrm{OVA}_{257-264}$ peptide [42] (Fig. 3a). Adoptive transfer (ID) of TCL-loaded poly I:C-treated $\mathrm{CDC} 1 \mathrm{~s}$ from $\mathrm{H}-2 \mathrm{~K}^{\mathrm{bm} 1}$ mice led to similar induction of total cellularity and amount of CD8+ T cells in the iLN compared with WT cDC1s (Fig. 3d and Additional file 1: Figure S3b). In contrast, transfer of $\mathrm{cDC} 1 \mathrm{~s}$ from $\mathrm{H}-2 \mathrm{~K}^{\mathrm{bm} 1}$ mice resulted in reduced numbers and frequencies of activated CD44+ IFN $\gamma$-producing CD8+ T cells upon re-stimulation compared with WT cDC1s (Fig. 3e \& $\mathrm{f}$ and Additional file 1: Figure S3b). These results indicate that TCL-loaded cDC1s are cross-presenting the ex vivo acquired tumor $\mathrm{Ag}$ to induce CD8+ T cell responses from the endogenous repertoire in vivo.

\section{Vaccination with TCL-loaded CDC1s protects against melanoma engraftment}

Next, we investigated whether the TCL-loaded CDC1-induced tumor Ag-specific CD8+ T cell response would prevent a subsequent tumor challenge. To this end, we ID injected naive mice with B16-OVA TCL-loaded cDC1s, followed by a boost vaccination 5 days later and ID grafting of B16-OVA melanoma cells 30 days after vaccination (Fig. 4a). cDC1-vaccinated mice showed a marked reduction of tumor growth and improved survival compared with control mice (Fig. 4b \& c). These data show that ID administration of TCL-loaded cDC1s induces long-lasting anti-tumor effects.

Transfer of TCL-loaded CDC1s enhances tumor-Ag-specific T-cell presence in tumors and controls established cancer progression

In a subsequent approach, we aimed to analyze the efficacy of a cDC1-induced anti-cancer effector $\mathrm{T}$ cell response in a therapeutic cancer setting. To this end, we determined the potential of TCL-loaded CDC1s to limit progression of established orthotopic (ID) B16-OVA melanomas with an average size of $25 \mathrm{~mm}^{2}$ (Fig. 5a). ID 

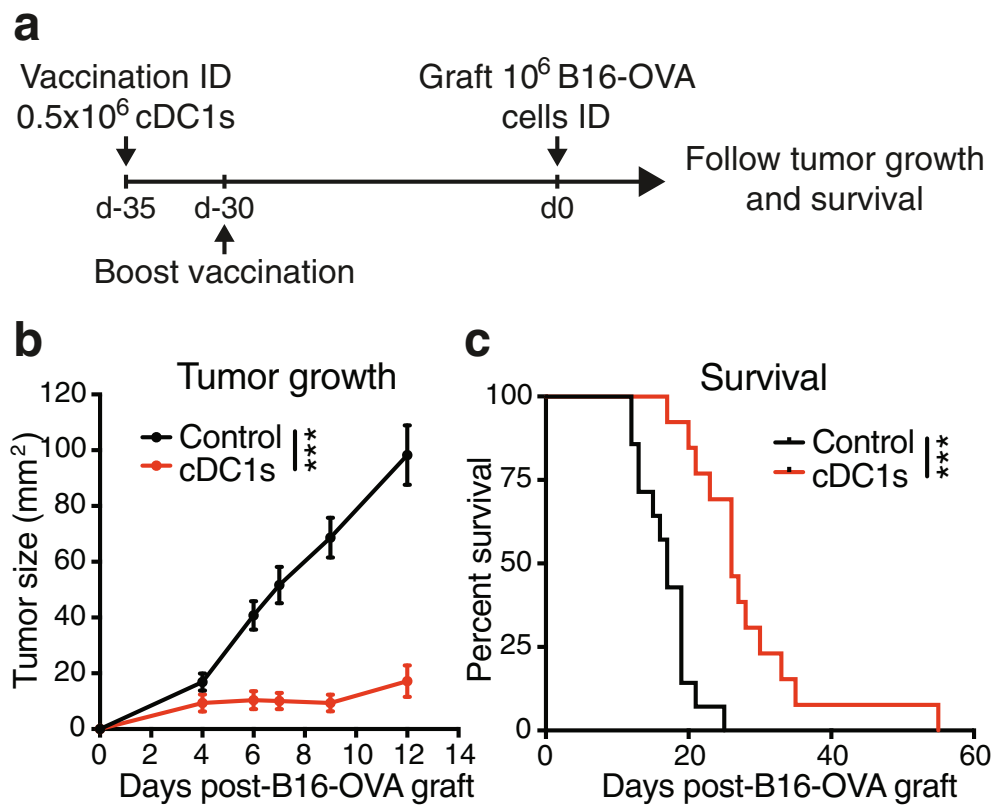

Fig. 4 Vaccination with TCL-loaded CDC1s protects against melanoma engraftment. a Schematic representation of treatment and analysis. PBS control or $0.5 \times 10^{6}$ poly I:C and autologous B16-OVA TCL-loaded CDC1s were intradermally (ID) injected 35 and 30 days prior to ID injection of $10^{6}$ B16-OVA cancer cells (day 0) and tumor growth and survival monitored. $\mathbf{b}$ Tumor growth and c survival curve of mice treated as described in (a). Combined data of 2 independent experiments with total $n=14$ (Control) and $n=13$ (cDC1s) mice are shown. ${ }^{* *} P<0.001$ by $\mathbf{b}$ Two-way ANOVA or c Mantel-Cox test

injection of B16-OVA TCL-loaded cDC1s halted tumor progression (Fig. 5b) and extended survival of tumorbearing mice to $>30 \%$ enhanced median survival compared with control mice (Fig. $5 \mathrm{c} \& \mathrm{~d}$ ). The timing of the melanoma growth control suggested the generation of an anti-cancer effector $\mathrm{T}$ cell response, therefore we analyzed $\mathrm{CD} 8+$ and $\mathrm{CD} 4+\mathrm{T}$ cells present in the tumordraining iLN (tdLN) (Fig. 5e-j and Additional file 1: Figure S4) and the grafted B16-OVA tumor (Fig. 5k-n and Additional file 1: Figure S5) 3 days after $\mathrm{CDC1}$ administration (Fig. 5a). Indeed, tumor-bearing mice treated with $\mathrm{cDC} 1 \mathrm{~s}$ exhibited larger tdLNs, and the number and frequency of PD-1-expressing CD44+ activated CD8+ and CD4+ T cells and $\mathrm{H}-2 \mathrm{~Kb}-\mathrm{OVA}_{257-264}+\mathrm{CD} 44+\mathrm{CD} 8+$ OVA-specific $\mathrm{T}$ cells was significantly enhanced in the tdLNs, while CD44+ OVA-specific CD4+ T cells remained unaltered (Fig. 5e \& h and Additional file 1: Figure S4a-c, f-h, k \& l). Notably, re-stimulation with $\mathrm{OVA}_{257-264}$ pep-

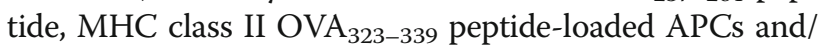
or B16-OVA TCL-loaded APCs of CD8+ and CD4+ T cells in tdLNs 3 days after TCL-loaded CDC1 injection resulted in strongly augmented IFN $\gamma$ production (Fig. 5f, g, i \& $j$ and Additional file 1: Figure S4d, e, i \& j).

We next determined $\mathrm{T}$ cell presence in the tumor 3 days after $\mathrm{cDC} 1$ treatment. At this time point, tumor size and frequency of total or PD-1-expressing CD8+ and CD4+ T cells, as well as OVA-specific CD4+ T cells in the tumor was equal (Additional file 1: Figure S5a-c \& e-g). In contrast, the frequency of tumor Ag-specific $\mathrm{H}-2 \mathrm{~Kb}-\mathrm{OVA}_{257-264}+\mathrm{CD} 8+\mathrm{T}$ cells was strongly increased after TCL-loaded $\mathrm{cDC} 1$ treatment (Additional file 1: Figure S5d). Moreover, a significantly enhanced frequency of $\mathrm{CD} 8+$ and $\mathrm{CD} 4+\mathrm{T}$ cells producing IFNY upon re-stimulation with $\mathrm{OVA}_{257-264}$ peptide, $\mathrm{OVA}_{323-}$ 339 peptide-loaded APCs and/or B16-OVA TCL-loaded APCs were detected in tumors of $\mathrm{CDC} 1$ vaccinated mice (Fig. 5k-n). Our results establish the efficacy of ID-administered natural $\mathrm{cDC} 1 \mathrm{~s}$ loaded with syngeneic cell death-induced TCL for therapeutic treatment of established orthotopic melanoma. Mechanistically, administration of cDC1s increases tumor Ag-specific effector CD8+ T cells and recall responses of CD8+ and CD4+ T cells in the tdLN and the tumor short before the decrease in tumor growth becomes significant.

\section{Treatment with TCL-loaded CDC1 strongly improves anti-PD-1 therapy}

In order to put the treatment with TCL-loaded natural cDC1s into the context of current therapies, we compared and combined it with immune checkpoint inhibition. MC38 colon adenocarcinoma, a wildtype tumor model that does not express any exogenous or dominant Ags, was chosen as a tumor partially susceptible to anti-PD-1 therapy when grafted subcutaneously [28]. UV irradiation of MC38 cancer cells induced HMGB1 release (Additional file 1: Figure S6a). Moreover, ex vivo $\mathrm{cDC} 1$ treatment with 


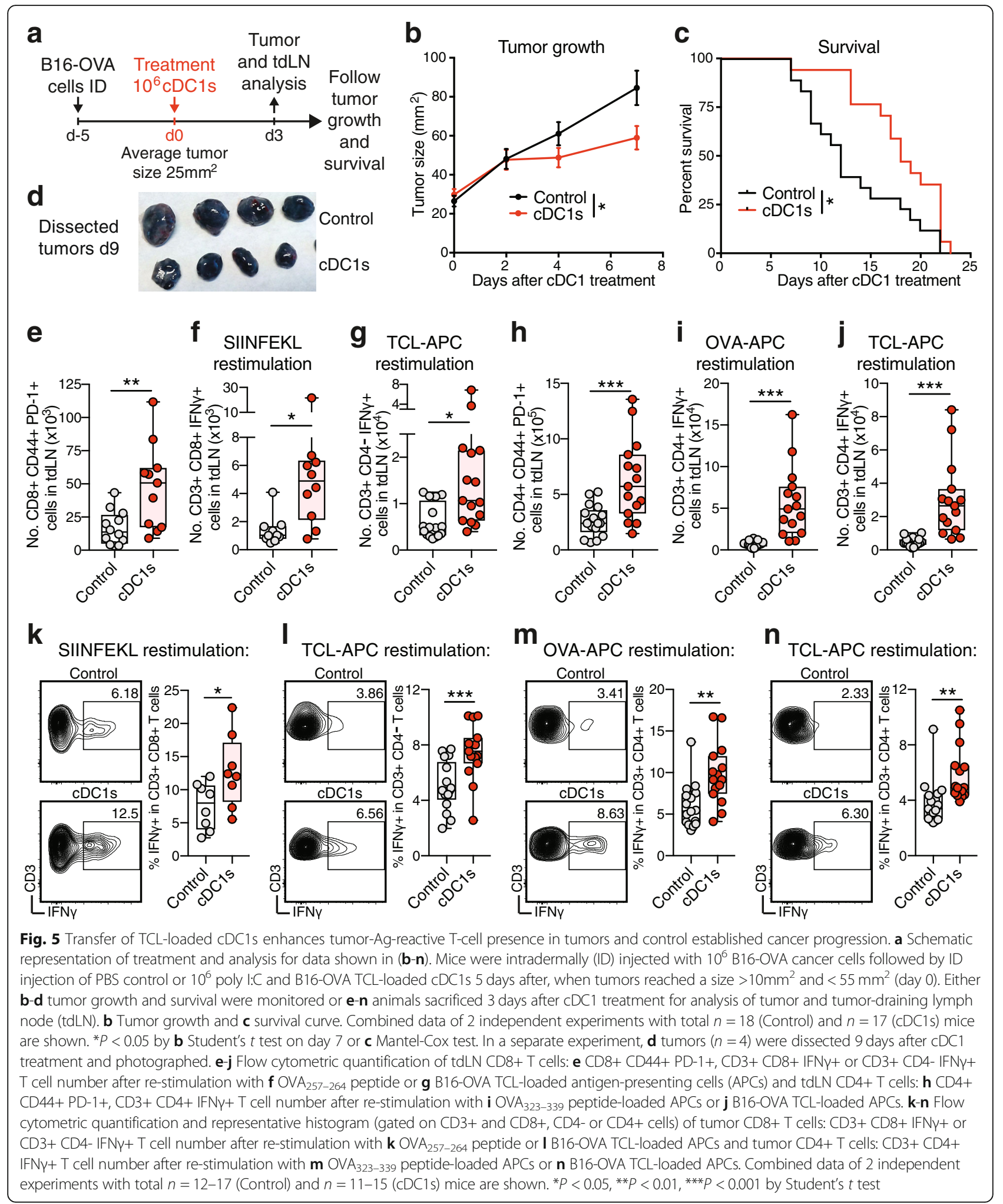

UV irradiation-generated MC38 TCL resulted in upregulation of CD86 and MHC-II, however not further increasing poly I:C-mediated $\mathrm{CDC} 1$ activation (Additional file 1: Figure S6b \& c). MC38 tumor-bearing mice were treated with $\mathrm{CDC} 1 \mathrm{~s}$ loaded with MC38 TCL when tumors were visible (day 6) and 1 week later (day 13). Further, mice received intraperitoneal (IP) injections of anti-PD-1 antibody on days 7, 10, 14 and 17 (Fig. 6a). MC38 TCL-loaded 


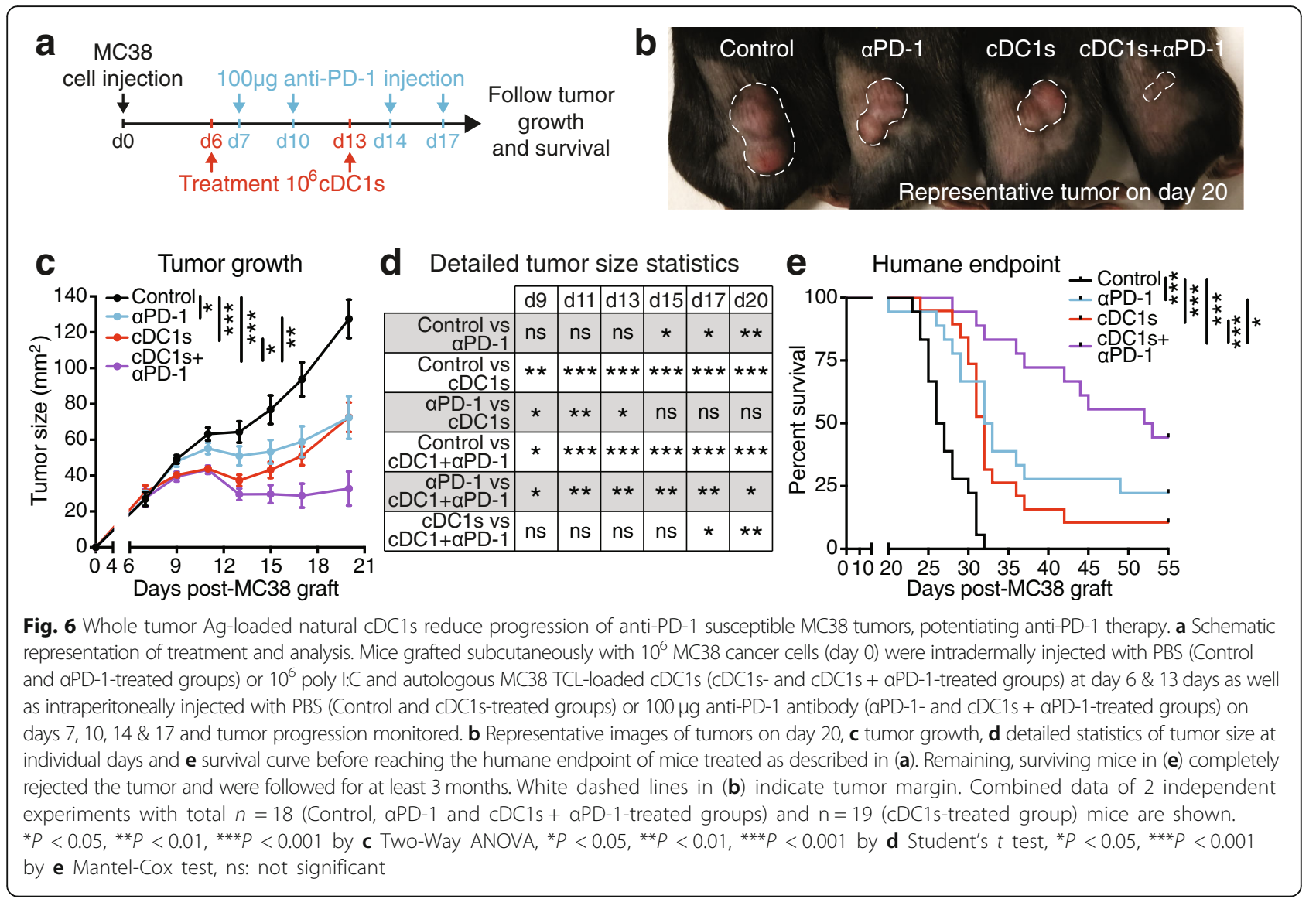

cDC1 administration was overall equally efficient as anti-PD-1 therapy in decreasing MC38 tumor progression and extending survival of mice before reaching the humane endpoint compared with control PBS treatment (Fig. 6b-e and Additional file 1: Figure S6d). Interestingly, cDC1-treated mice showed a faster therapeutic effect (Fig. 6c \& d), despite almost equal timing of treatment start and more frequent administration of anti-PD-1 antibody (Fig. 6a). Notably, combined treatment of MC38 tumor-bearing mice with TCL-loaded $\mathrm{CDC} 1 \mathrm{~s}$ and anti-PD-1 was more effective than single treatments, with complete tumor rejection in 8/18 mice (Fig. 6b-e and Additional file 1: Figure S6d). These results support that adoptive immunotherapy with TCL-loaded natural $\mathrm{cDC} 1 \mathrm{~s}$ improves anti-PD-1 treatment, significantly extending survival and doubling the number of mice cured from grafted tumors.

Immunotherapy with TCL-loaded CDC1s extends survival of anti-PD-1-refractory B16/F10 melanoma-bearing mice We next tested therapeutic efficacy of $\mathrm{CDC} 1$ administration in established ID engrafted B16/F10 melanoma, a very aggressive tumor that does not express exogenous or dominant Ags and is largely refractory to anti-PD-1 therapy [28, 43]. UV irradiation also induced ICD of
B16/F10 melanoma cells, as indicated by HMGB1 release and upregulation of MHC-II and CD86, which remained higher even upon poly I:C addition, on $\mathrm{CDC} 1 \mathrm{~s}$ exposed to B16/F10 TCL (Additional file 1: Figure S6e-g). Natural cDC1s loaded with syngeneic B16/F10 TCL were ID injected 6 and 13 days after grafting of B16/F10-melanomas onto recipient mice, when tumors were clearly visible. Anti-PD-1 antibody was IP injected on day 7, 10, 14 and 17 (Fig. 7a) and cancer progression monitored. As expected, mono-therapy with anti-PD-1 antibody did not significantly alter B16/F10 tumor growth or survival as compared with control PBS administration (Fig. 7b \& c). Notably, treatment with B16/F10 TCL-loaded cDC1s reduced progression of established B16/F10 melanomas as compared with control mice, while combined administration of anti-PD-1 and TCL-loaded cDC1s mirrored the efficacy of $\mathrm{cDC1}$ mono-treatment (Fig. $7 \mathrm{~d}$ $\&$ e). These results suggest that anti-PD-1-refractory cancers could benefit from immunotherapy with ICDinduced TCL-loaded natural cDC1s.

\section{Discussion}

The superior ability of mouse $\mathrm{cDC} 1 \mathrm{~s}$ to transport tumor-Ag to LNs, cross-present cancer cell-associated Ags and mediate infiltration of $\mathrm{T}$ cells in the tumor is 

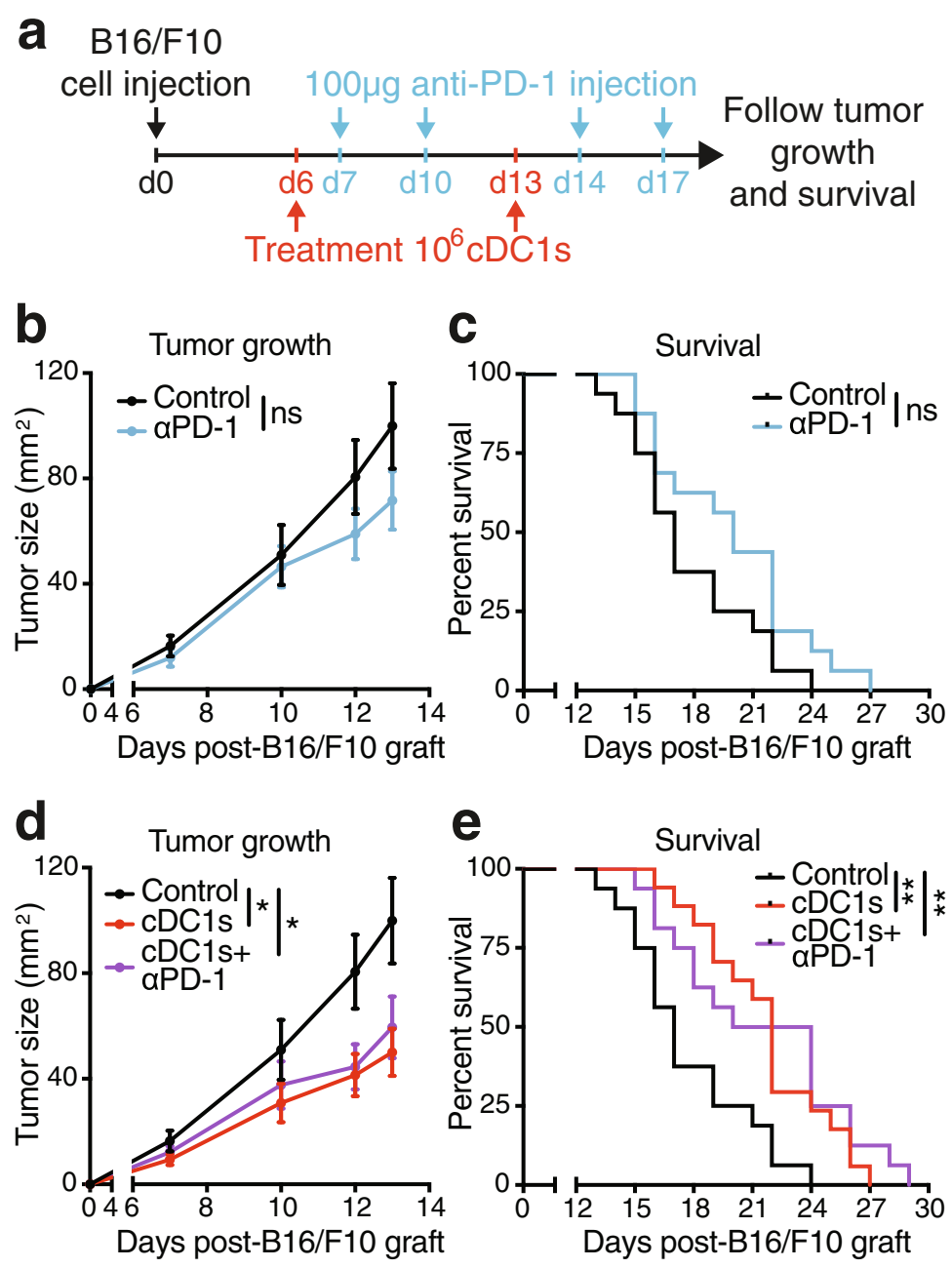

Fig. 7 Cell death-induced tumor Ag-loaded CDC1s are effective for treatment of largely anti-PD-1 refractory B16/F10 melanoma. a Schematic representation of treatment and analysis. Mice grafted intradermally (ID) with $5 \times 10^{5}$ B16/F10 cancer cells (day 0) were ID injected with PBS control (Control and aPD-1-treated groups) or $10^{6}$ poly l:C and autologous B16/F10 TCL-loaded CDC1s (CDC1s- and CDC1s + aPD-1-treated groups) at day $6 \& 13$ as well as intraperitoneally injected with PBS control (Control and cDC1s-treated groups) or $100 \mu \mathrm{mg}$ anti-PD-1 antibody (aPD-1and CDC1s + aPD-1-treated groups) at day 7, 10, 14 \& 17 and tumor growth and survival monitored. $\mathbf{b}$ \& $\mathbf{d}$ Tumor growth and $\mathbf{c}$ \& e survival curve of mice treated as described in (a). The same control group (black) is presented in (b \& $\mathbf{d}$ ) as well as in (c \& e), because data belong to the same experiment and are split for clarity. The graphs are displayed separately for better visibility. Combined data of 2 independent experiments with total $n=16$ (Control, aPD-1 and CDC1s + aPD-1-treated groups) and $n=17$ (cDC1s-treated group) mice are shown. ${ }^{*} P<0.05$ by $\mathbf{b} \&$ d Student's $t$ test at day 12 and 13 and ${ }^{* *} P<0.01$ by $\mathbf{c} \&$ e Mantel-Cox test, ns: not significant

established [14, 22, 29-31]. However, the efficiency of adoptive transfer of syngeneic natural circulating cDC1s for immunotherapy of cancer has not been previously tested. This study reveals the efficacy and feasibility of cancer-Ag loaded naturally occurring mouse $\mathrm{CDC1} 1 \mathrm{~s}$ for treatment of cancer. This next-generation DC vaccine employs: (A) the conventional cDC1 subset purified from tumor-bearing mice that excels in cross priming and elicits the strongest anticancer CD8+ $\mathrm{T}$ cell responses [22, 44]; (B) the use of poly I:C as an adjuvant that targets $\mathrm{CDC} 1 \mathrm{~s}$ via TLR3 and induces immunogenic activation, equivalent to adjuvants currently tested for clinical use [27]
(ClinicalTrials.gov identifier: NCT02828098); (C) cDC1loading with a total tumor Ag preparation based on UV irradiation-induced ICD of cancer cells, a method reported to exhibit superior immunogenic potential [35, 37, $45,46]$, releasing HMGB1 and activating $\mathrm{CDC1}$ s upon exposure; (D) a convenient route of administration; and (E) a time-efficient, economic and easy-to-use preparation protocol with translational potential.

FLT3L-mediated expansion of DCs facilitated isolation of mouse CD8+ cDC1s from the spleen of tumor-bearing mice. Amplification of DCs by administration of FLT3L in cancer patients is well-tolerated and might even have anti-cancer immunotherapeutic effects by 
itself in humans and mice $[9,29,47]$. Separation of natural CD1c + cDCs (cDC2s) and BDCA4+ pDCs from human leukapheresis products without the need for fluorescence-activated cell sorting and in good manufacturing practice (GMP) conditions was already achieved $[16,17]$ and technological advances will hopefully soon make GMP isolation of human BDCA3+ $\mathrm{CDC} 1$ s possible (PROCROP Cancer Immunotherapy European Initiative Web Site. http://www.procrop.eu (2015); accessed 25 Feb 2019).

Herein, we establish the proof of principle that mouse natural $\mathrm{cDC1}$ s treated ex vivo with adjuvant and tumor-Ag for a very short time are efficient to induce Ag-specific anti-cancer CD8+ and CD4+ $\mathrm{T}$ cell responses in vivo. UV irradiation followed by secondary necrosis and generation of TCL from three different cancer cell lines served as source of immunogenic tumor cell $\mathrm{Ag}$ for $\mathrm{cDC} 1 \mathrm{~s}$. Loading of $\mathrm{cDC} 1 \mathrm{~s}$ with cell death-induced TCL caused much more effective induction of $\mathrm{CD} 8+\mathrm{T}$ cell activation than loading $\mathrm{CDC} 1 \mathrm{~s}$ with soluble protein. This result highlights that UV irradiation-induced TCL not only contains a plethora of tumor cell-associated Ags, but also danger signals like HMGB1 that activate $\mathrm{CDC} 1 \mathrm{~s}$ and their capacity for tumor Ag processing [35, 37, 40, 41, 45, 46]. Indeed, some cytostatic agents, such as anthracyclines and UV irradiation, induce ICD associated with a spatiotemporal release of danger-associated molecular patterns (such as calreticulin, ATP, HMGB1 and F-actin). Thereby, in contrast to apoptosis that has rather tolerogenic effects, ICD acts as potent stimulator of adaptive immunity, which depends on the presence of DCs [37-41, 45]. RIPK1 signaling and NF- $\kappa B$-induced transcription in dying tumor cells also increase cross-priming efficiency and anti-tumor immunity [48]. Cell-associated danger signals associated with ICD like calreticulin promote phagocytosis, while adjuvants such as HMGB1 or F-actin induce DC activation, tumor $\mathrm{Ag}$ processing and cross-presentation [40, 41, 45, 49]. This is consistent with our results showing that UV irradiation causes HMGB1 release from three different mouse cancer cells lines and soluble factors in the resulting TCL induce DC activation. Moreover, treatment of natural $\mathrm{cDC} 1 \mathrm{~s}$ with both poly I:C adjuvant and TCL derived from UV-dead cells is needed for optimal CD8+ $\mathrm{T}$ cell cross-priming. Accordingly, a recent study showed that the combination of poly I:C activation and provision of necrotic cell-associated material caused human BDCA3+ $\mathrm{cDC} 1 \mathrm{~s}$ to outperform $\mathrm{CD} 1 \mathrm{c}+\mathrm{CDC} 2$ and moDC subsets in Ag uptake, internalization and cross-presentation [50].

The here reported next-generation cDC1-based anticancer vaccine strongly induced anti-cancer effector $\mathrm{CD} 8+\mathrm{T}$ cell responses from the endogenous repertoire in the skin-draining LN. Those responses appear to largely depend on the MHC class I-mediated presentation of the $\mathrm{Ag}$ loaded ex vivo onto $\mathrm{CDC} 1 \mathrm{~s}$, because $\mathrm{H}-2 \mathrm{~K}^{\mathrm{bm} 1} \mathrm{cDC} 1 \mathrm{~s}$, which fail to efficiently present $\mathrm{OVA}_{257-264}$ peptide on MHC-I [42], were significantly less potent than WT cDC1s. Notwithstanding, vaccination with $\mathrm{H}-2 \mathrm{~K}^{\mathrm{bm1}}$-harboring $\mathrm{cDC} 1 \mathrm{~s}$ induced some degree of specific $\mathrm{CD} 8+\mathrm{T}$ cell response, suggesting that $\mathrm{CDC} 1 \mathrm{~s}$ may also transfer ex vivo obtained $\mathrm{Ag}$ to endogenous Ag presenting cells upon injection in vivo, consistent with a role of cDC1s in tumor Ag transport to tdLNs $[29,30]$.

$\mathrm{CD} 8+$ and $\mathrm{CD} 4+\mathrm{T}$ cell activation induced by administration of TCL-loaded $\mathrm{CDC} 1 \mathrm{~s}$ contributes to reduced tumor progression and even remission of established tumors derived from the three cancer cell lines B16-OVA, B16/F10 and MC38, the latter two not expressing exogenous Ags. The effector tumor Ag-specific and cancer-reactive $\mathrm{CD} 8+$ and $\mathrm{CD} 4+\mathrm{T}$ cell response from the endogenous repertoire is enhanced both in the tumor and tdLN and precedes delays in tumor growth.

Moreover, our next-generation $\mathrm{cDC} 1$ anti-cancer vaccine was also effective in a preventive cancer setting, suggesting induction of enduring immune responses and probably the formation of immune memory, which would indicate a potential efficacy preventing metastasis. Moreover, $\mathrm{cDC} 1 \mathrm{~s}$ were shown to contribute to optimal generation of tissue-resident memory CD8+ T cells [51], a memory subset that promotes anti-tumor immunity in concert with circulating memory CD8+ T cells [52]. This observation may have implications for adjuvant vaccination in postsurgical minimal residual disease settings.

Anti-PD-1 therapy is the current standard treatment for many cancer types [3, 4]. Efficacy of therapy with PD-1 blockade in mouse cancer models is dependent on cDC1s $[28,29]$. In addition, we observe that administration of TCL-loaded cDC1s increased PD-1+ CD8+ and $\mathrm{CD} 4+\mathrm{T}$ cell numbers in tdLNs. Therefore, it was important to compare and combine our next-generation cDC1 anti-cancer vaccine with anti-PD-1 blockade. Tumor Ag-loaded cDC1 mono-therapy was equally successful as anti-PD-1 treatment in grafted MC38 tumors. Notably, cDC1 administration was immediately effective, suggesting that it enlarges the pool of anti-cancer T cells which could explain the synergism of combination therapy with anti-PD-1 blockade in this model. Administration of TCL-loaded CDC1 is also effective in B16/F10 tumors, which are anti-PD-1-refractory [28]. This result supports the notion that DC-based cancer immunotherapy can act in synergy and go beyond checkpoint antibody therapy, which is crucial to improve treatment for tumors resistant to current strategies [4, 8, 22].

We have established the proof of principle showing that adoptive transfer of TCL-loaded and adjuvant-activated $\mathrm{cDC} 1 \mathrm{~s}$ is effective in cancer immunotherapy. However, we intentionally did not compare this therapy 
with administration of other DC subsets in the mouse system. Apart from the only clinically approved Sipuleucel-T treatment [7], there is currently no gold standard for DC therapy regarding DC subset, incubation time, $\mathrm{Ag}$ and/or adjuvant that would serve for comparison in humans [10], and less so in mice. Moreover, while $\mathrm{CDC} 1 \mathrm{~s}$ specialize on cross-presentation of cell-associated Ags in the mouse, the unique functions of the human $\mathrm{CDC} 1$ equivalents are also debated [15, 18-22]. Notably, analysis of several datasets including The Cancer Genome Atlas (TCGA) suggest that a $\mathrm{CDC1}$ signature within many human tumors is associated with improved survival [26, 30, 32, 33]. Nonetheless, anti-cancer effects of DC-based vaccines will likely depend on numerous factors, including the nature of potential Ags available for a certain tumor type (identified neoantigens or tumor peptides, etc.) and, hence, the Ag and adjuvant cocktail used to load DCs. In addition, different tumors may benefit from generation of distinct types of immunity: for instance, a cDC2-dependent Th17 response may be beneficial in certain cancer models [53].

\section{Conclusions}

Our proof-of-principle study provides, for the first time, pre-clinical data showing suitability and efficacy of therapeutic cross-presenting cDC1-based vaccination. Overall, our results suggest a feasible scenario for patient treatment based on administration of tumor-Ag-loaded cDC1s. We show efficacy of a cDC1-based therapy that does not require identification of tumor neoantigens, representing an easily achievable personalized Ag source for virtually any resected tumor. Circulating $\mathrm{CDC} 1 \mathrm{~s}$ isolated from leukapheresis products of patients, eventually undergoing additional treatments with FLT3L to enhance $\mathrm{CDC1}$ numbers, can then be shortly exposed to autologous tumor-Ag and adjuvant before reinfusion. This strategy would reduce long-term cell cultures that make the process labor intensive and reduce reproducibility. Our results show the potential of this cDC1-based vaccine to be combined with standard anti-PD-1 therapy [54] or used in anti-PD-1 resistant tumors, inducing both effector and long-lasting anti-tumor $\mathrm{CD} 8+$ and $\mathrm{CD} 4+\mathrm{T}$ cell responses. These prospects will be tested as soon as GMP isolation of human natural $\mathrm{cDC} 1 \mathrm{~s}$ is feasible.

\section{Additional file}

Additional file 1: Figure S1. Isolation and phenotypic analysis of CDC1S from the spleen of FLT3L-expressing B16 tumor-bearing mice. Figure S2. Syngeneic TCL preparation for CDC1 maturation and CDC1-specific induction of T cell activation in vivo. Figure S3. Adoptive CDC1 transfer-mediated endogenous CD8+ $T$ cell responses are dependent on presentation on MHC-I of tumor Ag loaded onto CDC1s. Figure S4. Analysis of T cells in tumor-draining lymph node after administration of tumor Agloaded $\mathrm{CDC}$ 1s. Figure $\mathbf{S 5}$. Analysis of T cells in tumor after administration of tumor Ag-loaded CDC1s. Figure S6. UV irradiation-induced ICD of MC38 and B16/F10 cancer cells results in HMGB1 release and CDC1 activation. (PDF $3157 \mathrm{~kb})$

\section{Abbreviations}

Ag: Antigen; B16-FLT3L: FLT3L-expressing B16 melanoma cells; B16OVA: OVA-expressing B16 melanoma cells; CD8+ CTLs: Cytotoxic CD8+ T lymphocytes; CDC1: Conventional type 1DC; CDC2: Conventional type 2 DC; DC: Dendritic cell; FLT3L: FMS-like tyrosine kinase 3 ligand; GMP: Good manufacturing practice; $\mathrm{H}-2 \mathrm{~K}^{\mathrm{bm} 1}$ mice: C57BL/6 $6^{\mathrm{H} 2 \mathrm{Kbm} 1}$ mice; HMGB1: Highmobility group box protein 1; ICD: Immunogenic cell death; ID: Intradermal; iLN: Inguinal LN; IP: Intraperitoneal; ISQAVHAAHAEINEAGR: OVA $_{323-339}$ peptide; IV: Intravenous; LN: Lymph node; moDCs: Monocyte-derived DCs; o/ n: Overnight; OVA: Ovalbumin; pDC: Plasmacytoid DC; SIINFEKL: OVA $257-264$ peptide; TCL: Tumor cell lysate; tdLN: Tumor-draining iLN; TLR3: Toll-like receptor 3; UV: Ultraviolet

\section{Acknowledgements}

We thank all members of the D.S. laboratory at CNIC, the PROCROP consortium, Caetano Reis e Sousa and Noelia Casares for scientific discussions and support. We are thankful to CNIC core facilities, technical units, technicians and assistants for valuable technical assistance. We are indebted to all the scientists who have shared reagents, as indicated in Methods. We acknowledge the NIH Tetramer Core Facility (Emory University, contract HHSN272201300006C) for provision of MHC-II tetramers.

\section{Funding}

Work in the DS laboratory is funded by the CNIC and grant SAF2016-79040-R from Ministerio de Ciencia, Innovación e Universidades (MCIU), Agencia Estatal de Investigación and Fondo Europeo de Desarrollo Regional (FEDER); B2017/ BMD-3733 Immunothercan-CM from Comunidad de Madrid; RD16/0015/0018REEM from FIS-Instituto de Salud Carlos III, MICINN and FEDER; Acteria Foundation; Constantes y Vitales prize (Atresmedia); La Marató de TV3 Foundation (201723); and the European Research Council (ERC-2016-Consolidator Grant 725091). Work at the IM laboratory is funded by grants from MCIU (SAF2014-52361-R and SAF2017-83267-C2-1-R) and by European Commission VII Framework and Horizon 2020 programs (AICR), Fundación de la Asociación Española Contra el Cáncer (AECC), and Fundación BBVA. SKW is supported by a European Molecular Biology Organization Long-term Fellowship (grant ALTF 4382016) and a CNIC-International Postdoctoral Program Fellowship (grant 172302016). SCK is a recipient of a FPU fellowship (FPU16/03142) from the Spanish Ministry of Education, Culture and Sports. IM and DS labs are funded by the European Commission (635122-PROCROP H2020). The CNIC is supported by the MCIU and the Pro-CNIC Foundation, and is a Severo Ochoa Center of Excellence (SEV-2015-0505).

\section{Availability of data and materials}

All data generated and analyzed during this study are included within this published article and its Additional files. Further details are available from the corresponding author on reasonable request.

\section{Authors' contributions}

SKW conceptualized the studies, designed experiments, developed methodologies, performed research and experiments, analyzed and interpreted the data, and wrote the manuscript. JAI, RCG and SCK provided expertise, helped developing methodologies, performed experiments, helped analyzing data, and edited the manuscript. IM conceptualized the studies, supported design of experiments, analysis, and interpretation of data, edited the manuscript and contributed to funding acquisition. DS conceptualized the studies, designed experiments, interpreted the data, wrote the manuscript, contributed to funding acquisition, project administration and supervised the study. All authors read and approved the final manuscript.

\section{Ethics approval and consent to participate}

The local ethics committee approved all animal studies. All animal procedures conformed to EU Directive 2010/63EU and Recommendation 2007/526/EC regarding the protection of animals used for experimental and other scientific purposes, enforced in Spanish law under Real Decreto 1201/2005. 


\section{Consent for publication}

Not applicable.

\section{Competing interests}

IM reports receiving commercial research grants from BMS and ROCHE and serves as a consultant/advisory board member for BMS, Merck-Serono, Roche-Genentech, Genmab, Incyte, Bioncotech, Tusk, Molecular partners F-STAR, Alligator and AstraZeneca. The authors have no additional financial interests.

\section{Publisher's Note}

Springer Nature remains neutral with regard to jurisdictional claims in published maps and institutional affiliations.

\begin{abstract}
Author details
'Immunobiology Laboratory, Centro Nacional de Investigaciones Cardiovasculares (CNIC), Melchor Fernández Almagro, 3, 28029 Madrid, Spain. ${ }^{2}$ Division of Immunology and Immunotherapy, Center for Applied Medical Research (CIMA), University of Navarra, and Instituto de Investigación Sanitaria de Navarra (IdISNA), Pamplona, Spain. ${ }^{3}$ University Clinic, University of Navarra and Instituto de Investigación Sanitaria de Navarra (IdISNA), Pamplona, Spain. ${ }^{4}$ Centro de Investigación Biomédica en Red Cáncer (CIBERONC), Madrid, Spain
\end{abstract}

\section{Received: 22 November 2018 Accepted: 12 March 2019} Published online: 08 April 2019

\section{References}

1. Durgeau A, Virk Y, Corgnac S, Mami-Chouaib F. Recent advances in targeting CD8 T-cell immunity for more effective Cancer immunotherapy. Front Immunol. 2018:9:14.

2. Singer M, Wang C, Cong L, Marjanovic ND, Kowalczyk MS, Zhang H, et al. A distinct gene module for dysfunction uncoupled from activation in tumorinfiltrating T cells. Cell. 2016;166:1500-11.

3. Ribas A, Wolchok JD. Cancer immunotherapy using checkpoint blockade. Science. 2018;359:1350-5.

4. Whiteside TL, Demaria S, Rodriguez-Ruiz ME, Zarour HM, Melero I. Emerging opportunities and challenges in Cancer immunotherapy. Clin Cancer Res. 2016;22:1845-55

5. Saxena M, Bhardwaj N. Re-emergence of dendritic cell vaccines for Cancer treatment. Trends Cancer. 2018;4:119-37.

6. Melero I, Gaudernack G, Gerritsen W, Huber C, Parmiani G, Scholl S, et al. Therapeutic vaccines for cancer: an overview of clinical trials. Nat Rev Clin Oncol. 2014;11:509-24.

7. Anassi E, Ndefo UA. Sipuleucel-T (provenge) injection: the first immunotherapy agent (vaccine) for hormone-refractory prostate cancer. P T. 2011;36:197-202.

8. Garg AD, Coulie PG, Van den Eynde BJ, Agostinis P. Integrating nextgeneration dendritic cell vaccines into the current Cancer immunotherapy landscape. Trends Immunol. 2017;38:577-93.

9. Saxena M, Bhardwaj N. Turbocharging vaccines: emerging adjuvants for dendritic cell based therapeutic cancer vaccines. Curr Opin Immunol. 2017; 47:35-43.

10. Wimmers F, Schreibelt G, Sköld AE, Figdor CG, De Vries IJM. Paradigm shift in dendritic cell-based immunotherapy: from in vitro generated monocytederived DCs to naturally circulating DC subsets. Front Immunol. 2014:5:165.

11. Boudewijns S, Bloemendal M, Gerritsen WR, de Vries IJM, Schreibelt G. Dendritic cell vaccination in melanoma patients: from promising results to future perspectives. Hum Vaccin Immunother. 2016;12:2523-8

12. Bol KF, Schreibelt G, Gerritsen WR, de Vries IJM, Figdor CG. Dendritic cellbased immunotherapy: state of the art and beyond. Clin Cancer Res. 2016; 22:1897-906.

13. Sittig S, de Vries I, Schreibelt G. Primary human blood dendritic cells for Cancer immunotherapy_-tailoring the immune response by dendritic cell maturation. Biomedicines. 2015;3:282-303.

14. Böttcher JP, Reis E Sousa C. The role of type 1 conventional dendritic cells in Cancer immunity. Trends Cancer. 2018;4:784-92.

15. Collin M, Bigley V. Human dendritic cell subsets: an update. Immunology. 2018;154:3-20

16. Tel J, Aarntzen EHJG, Baba T, Schreibelt G, Schulte BM, Benitez-Ribas D, et al. Natural human plasmacytoid dendritic cells induce antigen-specific T-cell responses in melanoma patients. Cancer Res. 2013;73:1063-75.
17. Schreibelt G, Bol KF, Westdorp H, Wimmers F, Aarntzen EHJG, Duiveman-de Boer $\mathrm{T}$, et al. Effective clinical responses in metastatic melanoma patients after vaccination with primary myeloid dendritic cells. Clin Cancer Res. 2016; 22:2155-66.

18. Bachem A, Güttler S, Hartung E, Ebstein F, Schaefer M, Tannert A, et al. Superior antigen cross-presentation and XCR1 expression define human CD11c + CD141 + cells as homologues of mouse CD8 + dendritic cells. J Exp Med. 2010;207:1273-81.

19. Crozat K, Guiton R, Contreras V, Feuillet V, Dutertre C-A, Ventre E, et al. The XC chemokine receptor 1 is a conserved selective marker of mammalian cells homologous to mouse CD8a + dendritic cells. J Exp Med. 2010;207:1283-92.

20. Jongbloed SL, Kassianos AJ, McDonald KJ, Clark GJ, Ju X, Angel CE, et al. Human CD141 + (BDCA-3) + dendritic cells (DCs) represent a unique myeloid DC subset that cross-presents necrotic cell antigens. J Exp Med. 2010;207:1247-60.

21. Poulin LF, Salio M, Griessinger E, Anjos-Afonso F, Craciun L, Chen J-L, et al. Characterization of human DNGR-1 + BDCA3 + leukocytes as putative equivalents of mouse CD8a + dendritic cells. J Exp Med. 2010;207:1261-71.

22. Sánchez-Paulete AR, Teijeira A, Cueto FJ, Garasa S, Pérez-Gracia JL, SánchezArráez A, et al. Antigen cross-presentation and T-cell cross-priming in cancer immunology and immunotherapy. Ann Oncol. 2017:28:xii44-55.

23. Martínez-López M, Iborra S, Conde-Garrosa R, Sancho D. Batf3-dependent CD103 + dendritic cells are major producers of IL-12 that drive local Th1 immunity against Leishmania major infection in mice. Eur J Immunol. 2015;45:119-29.

24. Ruffell B, Chang-Strachan D, Chan V, Rosenbusch A, Ho CMT, Pryer N, et al. Macrophage IL-10 blocks CD8+ T cell-dependent responses to chemotherapy by suppressing IL-12 expression in Intratumoral dendritic cells. Cancer Cell. 2014:26:623-37.

25. Hildner K, Edelson BT, Purtha WE, Diamond M, Matsushita H, Kohyama M, et al. Batf3 deficiency reveals a critical role for CD8 + dendritic cells in cytotoxic T cell immunity. Science. 2008;322:1097-100

26. Broz ML, Binnewies M, Boldajipour B, Nelson AE, Pollack JL, Erle DJ, et al. Dissecting the tumor myeloid compartment reveals rare activating antigenpresenting cells critical for T cell immunity. Cancer Cell. 2014;26:638-52.

27. Azuma M, Takeda Y, Nakajima H, Sugiyama H, Ebihara T, Oshiumi H, et al. Biphasic function of TLR3 adjuvant on tumor and spleen dendritic cells promotes tumor $\mathrm{T}$ cell infiltration and regression in a vaccine therapy. Oncoimmunology. 2016:5:e1188244.

28. Sanchez-Paulete AR, Cueto FJ, Martinez-Lopez M, Labiano S, MoralesKastresana A, Rodriguez-Ruiz ME, et al. Cancer immunotherapy with immunomodulatory anti-CD137 and anti-PD-1 monoclonal antibodies requires BATF3-dependent dendritic cells. Cancer Discov. 2016:6:71-9.

29. Salmon H, Idoyaga J, Rahman A, Leboeuf M, Remark R, Jordan S, et al. Expansion and activation of CD103 + dendritic cell progenitors at the tumor site enhances tumor responses to therapeutic PD-L1 and BRAF inhibition. Immunity. 2016;44:924-38.

30. Roberts EW, Broz ML, Binnewies M, Headley MB, Nelson AE, Wolf DM, et al. Critical role for CD103 + /CD141 + dendritic cells bearing CCR7 for tumor antigen trafficking and priming of T cell immunity in melanoma. Cancer Cell. 2016;30:324-36.

31. Spranger S, Dai D, Horton B, Gajewski TF. Tumor-residing Batf3 dendritic cells are required for effector $T$ cell trafficking and adoptive $T$ cell therapy. Cancer Cell. 2017:31:711-723.e4.

32. Böttcher JP, Bonavita E, Chakravarty P, Blees H, Cabeza-Cabrerizo M, Sammicheli $S$, et al. NK cells stimulate recruitment of $C D C 1$ into the tumor microenvironment promoting Cancer immune control. Cell. 2018; 172:1022-1037.e14.

33. Spranger S, Bao R, Gajewski TF. Melanoma-intrinsic $\beta$-catenin signalling prevents anti-tumour immunity. Nature. 2015;523:231-5.

34. Mach N, Gillessen S, Wilson SB, Sheehan C, Mihm M, Dranoff G. Differences in dendritic cells stimulated in vivo by tumors engineered to secrete granulocyte-macrophage colony-stimulating factor or Flt3-ligand. Cancer Res. 2000;60:3239-46

35. Sancho D, Joffre OP, Keller AM, Rogers NC, Martínez D, Hernanz-Falcón P, et al. Identification of a dendritic cell receptor that couples sensing of necrosis to immunity. Nature. 2009:458:899-903.

36. Palucka K, Banchereau J. Dendritic-cell-based therapeutic Cancer vaccines. Immunity. 2013:39:38-48.

37. Garg AD, Galluzzi L, Apetoh L, Baert T, Birge RB, Bravo-San Pedro JM, et al. Molecular and translational classifications of DAMPs in immunogenic cell death. Front Immunol. 2015;6:588. 
38. Galluzzi L, Buqué A, Kepp O, Zitvogel L, Kroemer G. Immunogenic cell death in cancer and infectious disease. Nat Rev Immunol. 2017;17:97-111.

39. Obeid M, Tesniere A, Ghiringhelli F, Fimia GM, Apetoh L, Perfettini J-L, et al. Calreticulin exposure dictates the immunogenicity of cancer cell death. Nat Med. 2007;13:54-61.

40. Apetoh L, Ghiringhelli F, Tesniere A, Obeid M, Ortiz C, Criollo A, et al. Tolllike receptor 4-dependent contribution of the immune system to anticancer chemotherapy and radiotherapy. Nat Med. 2007;13:1050-9.

41. Werthmöller N, Frey B, Wunderlich R, Fietkau R, Gaipl US. Modulation of radiochemoimmunotherapy-induced $B 16$ melanoma cell death by the pan-caspase inhibitor zVAD-fmk induces anti-tumor immunity in a HMGB1-, nucleotide- and T-cell-dependent manner. Cell Death Dis. 2015;6:1-11.

42. Nikolić-Žugić J, Carbone FR. The effect of mutations in the MHC class peptide binding groove on the cytotoxic T lymphocyte recognition of the kb-restricted ovalbumin determinant. Eur J Immunol. 1990;20:2431-7.

43. Overwijk WW, Restifo NP. B16 as a mouse model for human melanoma. In: current protocols in immunology. Hoboken: Wiley; 2001. p. Unit 201

44. Fehres CM, Unger WWJ, Garcia-Vallejo JJ, van Kooyk Y. Understanding the biology of antigen cross-presentation for the design of vaccines against Cancer. Front Immunol. 2014;5:149.

45. Ahrens S, Zelenay S, Sancho D, Hanč P, Kjæer S, Feest C, et al. F-actin is an evolutionarily conserved damage-associated molecular pattern recognized by DNGR-1, a receptor for dead cells. Immunity. 2012;36:635-45.

46. Kim TS, Gorski SA, Hahn S, Murphy KM, Braciale TJ. Distinct dendritic cell subsets dictate the fate decision between effector and memory CD8+ T cell differentiation by a CD24-dependent mechanism. Immunity. 2014:40:400-13.

47. Dong J, McPherson CM, Stambrook PJ. Flt-3 ligand: a potent dendritic cell stimulator and novel antitumor agent. Cancer Biol Ther. 2002;1:486-9.

48. Yatim N, Jusforgues-Saklani H, Orozco S, Schulz O, Da Silva RB, Reis E, Sousa $\mathrm{C}$, et al. RIPK1 and NF-kB signaling in dying cells determines cross-priming of CD8+ T cells. Science. 2015;350:328-34.

49. Iborra S, Izquierdo HM, Martínez-López M, Blanco-Menéndez N, Reis e Sousa C, Sancho D. The DC receptor DNGR-1 mediates cross-priming of CTLs during vaccinia virus infection in mice. J Clin Invest. 2012;122:1628-43.

50. Chiang M-C, Tullett KM, Lee YS, Idris A, Ding Y, McDonald KJ et al. Differentia uptake and cross-presentation of soluble and necrotic cell antigen by human DC subsets. Eur J Immunol. 2016:46:329-39.

51. Iborra S, Martínez-López M, Khouili SC, Enamorado M, Cueto FJ, CondeGarrosa R, et al. Optimal generation of tissue-resident but not circulating memory T cells during viral infection requires Crosspriming by DNGR-1 + dendritic cells. Immunity. 2016;45:847-60.

52. Enamorado M, Iborra S, Priego E, Cueto FJ, Quintana JA, Martínez-Cano S, et al. Enhanced anti-tumour immunity requires the interplay between resident and circulating memory CD8+ T cells. Nat Commun. 2017:8:16073.

53. Laoui $D$, Keirsse J, Morias $Y$, Van Overmeire E, Geeraerts $X$, Elkrim $Y$, et al. The tumour microenvironment harbours ontogenically distinct dendritic cell populations with opposing effects on tumour immunity. Nat Commun. 2016;7:13720.

54. Melero I, Berman DM, Aznar MA, Korman AJ, Pérez Gracia JL, Haanen J. Evolving synergistic combinations of targeted immunotherapies to combat cancer. Nat Rev Cancer. 2015;15:457-72.

Ready to submit your research? Choose BMC and benefit from:

- fast, convenient online submission

- thorough peer review by experienced researchers in your field

- rapid publication on acceptance

- support for research data, including large and complex data types

- gold Open Access which fosters wider collaboration and increased citations

- maximum visibility for your research: over $100 \mathrm{M}$ website views per year

At $\mathrm{BMC}$, research is always in progress.

Learn more biomedcentral.com/submissions 